\title{
Auto-Avaliação nas Organizações
}

\author{
AARON WILDAVSKY \\ Da Universidade de Califórnia (EE.UU.) \\ Tradução de Olga Ferrini de Faria
}

Fonte: Public Administration Review — set./out. de 1972

\begin{abstract}
Este documento é o primeiro capítulo de um livro sobre a alocação de recursos federais nos Estados Unidos, no campo da recreação. O orçamento detalhado era afetado politicamente, mas não ajudava na análise das atividades do órgão. O orçamento-programa não sofria essa influência, mas também não levava à avaliação. Isto chamou a atenção para a questão de porque as organizações resistem à avaliação. A tese do artigo é de que a avaliação é um problema organizacional, primordialmente. As necessidades da organização $\theta$ as pessoas dentro dela conflituam com o desejo de verificar continuamente as atividades e mudar diretrizes quando elas estão deixando a desejar. Considerando como uma organização inteiramente devotada à auto-avaliação poderia funcionar e como aş, pessoas poderiam sobreviver ao desejo dessa organização de manter recursos e objetivos sob tensão criativa, o artigo conclui que é difícil casar organização e avaliação. Ele apresenta sugestões para conciliar a avaliação substantiva e os imperativos da vida organizacional. Mas o grau de confiança entre os grupos sociais é visto como um regulador capital facilitando ou dificultando a avaliação e condicionando o seu aproveitamento.
\end{abstract}

Por Por que as instituições não avaliam constantemente suas atividades? qua que aparentam não manifestar uma auto-crítica, mesmo rudimentar? Por quanto tempo podem os indivíduos trabalhar num órgão sem conhecer seus qujetivos ou sem saber até onde tais objetivos foram atingidos? Fico perplexo quando penso no mal que decorre desse fato para os órgãos e acabo preocupado em saber porque assim procedem. Até certo ponto, os termos organização e avaliação provam-se, em última análise, contraditórios. Sem compreender que avaliação é às vezes incompatível com organização, somos tentados a crer em 
se estão ou não executando um trabalho útil. Se, em vez disso, nos propuséssemos questões mais inteligentes, não pareceríamos tão idiotas e não nos surpreenderíamos tanto.

Quem deve avaliar e quem deve administrar ? Como se dividirá o poder entre esses funcionários ? Qual deles arcará com o ônus das reformas ? Poderão os avaliadores manter-se suficientemente estáveis para levar avante o seu trabalho num ambiente tumultuado? Poder-se-á atribuir a autoridade ao avaliador e dividir a responsabilidade entre os administradores? Como convencer os administradores a coletar dados que possam ser úteis aos outros e somente prejudiciais a eles próprios ? Como obter apoio em nome de recomendaçóes que geram contrariedades? Os problemas políticos seriam resolvidos com a criação de uma organização especial - empresa de avaliação — integralmente devotada ao desempenho da função de análise? Poderia essa empresa conquistar o necessário apoio sem negligenciar sua missão de analisar ? Como conjugar o conhecimento com o poder?

\section{AVALIAÇÃo}

A organização ideal seria auto-avaliável. Verificaria continuamente suas próprias atividades de modo a determinar se está alcançando suas metas e se estas devem prevalecer. Quando a avaliação indicasse que seria desejável a mudança de programas e metas exatamente com o objetivo de alcançá-los tais proposições seriam levadas a sério pelos escalões decisórios superiores. Estes promoveriam as necessárias reformas e não teriam interesses consolidados na continuação das atividades em curso. Em vez disso buscariam insistentemente novas alternativas para melhor alcançar as novas metas fixadas.

O integrante ideal de uma organização auto-avaliável seria aquele que se revelasse como a pessoa capaz de certas técnicas de solução de problemas. Ele crê na importância de tornar claras as metas, relacionando-as com diferentes mecanismos de realização, criando modelos (às vezes quantitativos) para o relacionamento entre investimentos e resultados, procurando a melhor combinação possivel. Seu interesse não é pela sobrevivência da organização, pelo realce de um determinado objetivo específico ou pelo atendimento de uma clientela em particular. O avaliador cuida para que problemas interessantes sejam identificados e para que o máximo de talento seja aplicado na sua solução.

Para o homem capaz de avaliar, a organização não importa, salvo se atende a necessidades sociais. Os métodos não importam a não ser que facilitem o atendimento dessas necessidades. A eficiência é superada quando a consecução do objetivo a baixo custo torna-o inadequado. A obtenção de apoio político não significa que sejam bons os programas projetados para alcançar

R. Serv. públ., Brasília, 109 (2) abr./jun. 1974 
os objetivos. Significa apenas que tais programas tiveram mais votos do que outros. Tanto os objetivos como os recursos, dizem os bons avaliadores, devem ser constantemente modificados para que se consiga eficiente atendimento às necessidades sociais.

A avaliação não deve somente levar à descoberta de melhores programas visando à consecução das metas já perseguidas, mas também à sua modificação. A análise da eficiência e da política adotada levam à consideração de alternativas que justaponham meios e fins incorporados em planos alternativos. Os objetivos bem como os meios de alcançá-los podem ser considerados como impróprios. Mas os homens que se acostumaram a aceitar determinados objetivos podem mostrar-se hostis à mudança. A Resistência à inovação toma, então a forma de esforço pela preservação dos objetivos sociais.

As dificuldades são exageradas logo que se descubra que os objetivos podem estar intimamente relacionados com a clientela - o pobre, o homem da rua, o trabalhador - com os quais se identificam os integrantes da organização. Os objetivos desta podem tê-los atraído precisamente porque eles a vêm como meio de servir ao povo que valorizam. Podem por isso ver as mudanças de objetivos como proposta de trair os clientes a que desejavam servir. A seus olhos, a avaliação se torna inimiga do povo. O homem que avalia deve aprender a conviver com as contradições.
Deve reduzir seu comprometimento com a organização em que trabalha, com o programa que executa e com a clientela a que serve. O avaliador deve tornar-se agente da mudança atuando em favor de programas ainda por nascer e de clientelas ainda desconhecidas. Preparado para impor mudanças, ele deve ter suficiente estabilidade para levar avante seu trabalho. Deve manter sua própria organização enquanto se prepara para abandoná-la. Deve obter o apoio da burocracia enquanto busca impor uma política antiburocrática. Deve combinar a viabilidade política com a pureza analítica. Somente um audacioso pediria que tal combinação de qualidades fosse encontrada numa mesma pessoa e numa mesma organização.

Avaliação e organização podem ser expressões contraditórias. A estrutura organizacional implica em estabilidade enquanto o processo de avaliação sugere mudança. A organização gera compromisso e a avaliação estimula o ceticismo. Avaliação trabalha as relações entre ação e objetivos enquanto Organização relaciona suas atividades com os programas e a clientela. Ninguém pode afirmar com certeza que pode existir organização que se avalie, muito menos que esta se torne a forma dominante de administração. Muito se pode aprender a respeito de produção e emprego de avaliação no serviço público, estudando os requisitos para a obtenção de um estado de coisas tão extraordinário, isto é, uma organização auto-avaliável. 


\section{A REVISÃO DA DICOTOMIA POLITICA-ADMINISTRAÇÃO}

Organização exige divisão de trabalho. Ninguém pode fazer tudo. Quem, então, executará a função de avaliar a quem administrará os programas pelos quais a organização é responsável ?

Praticamente, toda organização tem uma equipe de programa seja qual for o seu título, que chama a atenção das altas autoridades para os problemas de política. Esse pessoal é restrito em número e faz a avaliação em uso na organização. Deve exercer considerável poder mediante sua capacidade de persuasão e seu acesso à alta direção, ou formará apenas uma excrescência no corpo da organização, podendo ser observada, mas que não causa qualquer efeito. Na medida em que alguém se interesse pelo desenvolvimento de atividades analíticas, deve interessar-se em reforçá-las relativamente a outros elementos. A idéia de organização auto-avaliadora tem de significar mais do que isso: alguns homens procuram introduzir avaliação numa organização centenas ou milhares de vezes maior do que eles próprios. O espírito de autoavaliação sugere que, de maneira de certo modo significativa, toda a organização está influenciada pela ética avaliativa.

Somos imediatamente colocados diante da linha de comando. Até que ponto das estruturas deve descer o espírito de avaliação para assegurar a reação da organização em geral ? Se todo o pessoal está envolvido, as dificuldades em encontrar mensageiros, escriturários e secretários que se ajustem aos critérios parecem insuperáveis.

Se subimos um degrau na direção daqueles que tratam com o público e desempenham tipos de atividades mais complexas, os números envolvidos poder ser ainda mais vacilantes. Essas dezenas de milhares de pessoas não têm certamente as qualificações necessárias para exercer atividades de avaliação e seria vão pretender que as tivessem. O guarda florestal e o encarregado de parques nacionais podem ser excelentes pessoas, mas não estão treinados para avaliar e não parece que possam sê-lo. Contudo a atividade de avaliação apropriada para cada nível deve ser encontrada se a avaliação vai penetrar toda a organizção.

Tem havido muita discussão nos círculos dirigentes a respeito da ar culação da descentralização com a atribuição de responsabilidade. Atribui-se autoridade às subunidades dentro de certos limites e elas são estritamente responsáveis perante seus superiores hierárquicos. O poder central é disfarçado mas existe. Dividindo a tarefa de modo que cada subunidade possua autonomia genuina significa deixá-las participar das decisões centrais, afetando toda a organização. Sabe-se que a descentralização existe até o ponto em que as unidades operacionais seguem diretrizes inconsistentes e contraditórias. Pode-se esperar que o órgão central tradicional - rivalidades regionais à parte

R. Serv. públ., Brasília, 109 (2) abr./jun. 1974 
seja o que enfatiza problemas e interesses locais, enquanto os outros temem dissolução, por fusão com outras unidades.

A tensão poderá manifestar-se em termos de análises rivais : o central vencerá devido à sua maior autoridade mas as unidades locais superam os especialistas em seus próprios problemas. Eles terão que ser postos nos seus devidos lugares. Voltamos, segundo parece, à questão da hierarquia. Como obter o centro o que deseja da periferia sem formalizar suas relações?

Um modelo, o giroscópio internalizado, é registrado por Herbert Kaufman's em seu clássico "The Forest Ranger". Através de recrutamento e treinamento os guardas florestais são socializados em valores centrais que levam consigo onde quer que vão e os aplicam a situações específicas. Consegue-se o controle central sem esforço aparente ou inúmeras instruções detalhadas para os guardas, porque estes internalizaram as premissas principais de que decorrem as ações apropriadas.

O problema da organização auto-avaliadora é mais difícil porque demanda solução de problemas divorciada de comprometimento com diretrizes e estruturas específicas. O nivel de competência requerido é consideravelmente mais elevado e a área de identificação de problemas é mais difusa. $O$ exército de Israel vem obtendo grande sucesso em difundir habilidade para solução de problemas em seus oficiais (em vez da execução de instruções pré-determinadas) (1). Mas sua identificação com a organização é muito mais intensa do que se pode verificar em qualquer outra parte.

Suponhamos que a maioria do pessoal de uma organização não tenha capacidade bastante para executar a avaliação. Suponhamos que seja oneroso demais movimentar centenas de milhares de funcionários públicos que executam 0 trabalho do governo. A alternativa imediata é transformar toda a administração central numa unidade avaliadora que dirija a organização. Há vários modelos universais autênticos. O que na Inglaterra se chamava a classe administrativa ilustra um tipo de decisão central. Ela se movimenta entre os grandes departamentos e procura (envolvidos os ministros políticos) dirigir as atividades da vasta burocracia que a cerca. Esse pessoal é selecionado pelas qualificações intelectuais que o capacitam para entender a política, bem como pelas qualidades comportamentais que lhes possibilitam conviver bem com seus companheiros. No ápice está o Tesouro, uma organização com pouco comprometimento operacional, cuja tarefa é a de dirigir as atividades da burocracia $\theta$ introduzir reformas quando necessárias. A política econômica, que é a área especial do Tesouro, está sujeita a sofrer rápidas mudanças e seu pessoal é de imediato usado para novas tarefas e objetivos. Muito embora divorciados de certa forma das organizações em que têm parcela de responsabilidade perante os ministros políticos, os altos servidores civis são também parte delas, em virtude de seus interesses administrativos diretos. Esses homens têm 
sido criticados por seu conservadorismo na defesa de interesses setoriais, sua preocupação com questões imediatas ou sua excessiva submissão a tradicionais vínculos organizacionais para que possam fazer avaliação a sério. Daí, segundo o Relatório Fulton, eles se adaptarem muito vagarosamente, - quando se adaptam, - às novas situações. Tentativas tem sido feitas visando a criar-se um Corpo Central de Revisão de Diretrizes para realizar as análises da política para o Gabinete e estimular, por outro lado, a atividade de avaliação.

A Alemanha e a Suécia têm avançado consideravelmente nessa direção. Os departamentos na Suécia são realmente pequenos grupos interessados em questões de política enquanto a administração é delegada a grandes empresas públicas criadas com esse propósito (2). Os governos estaduais na Alemanha (os Lander) realizam mais de $90 \%$ do trabalho administrativo, e os órgãos do governo central ocupam-se, presumivelmente, com assuntos mais importantes de política. O estudioso de administração pública na América do Norte verificará de imediato o que está ocorrendo. A dicotomia política-administraçăo, tão cara aos primitivos teóricos da administração americana, dicotomia esta completamente abandonada nas décadas de quarenta e cinqüenta, reapareceu subitamente com nova vitalidade.

A dicotomia política-administração nasceu com Frank Goodnow e outros em seus esforços para legitimar o advento do serviço civil e, com ele, a norma de neutralidade da administração. Eles procuravam proteger os bons governos contra os males do sistema de despojos isolando-os da política partidária. O Congresso fazia a política e a tarefa da máquina administrativa era encontrar meios técnicos adequados para executar essa política. Os atos ad. ministrativos deveriam ser menos generalistas e mais técnicos, de modo que os administradores bem motivados seriam capazes de realizar a vontade do povo, conforme formulada pelo Governo e Presidente da República. Podia-se então selecionar os servidores públicos na base do mérito e não em função de suas ligações partidárias ou de sua orientação política. Uma avalanche de críticas, iniciada com a obra "Policy and Administration", de Paul Appleby atacou esses argumentos por todos os lados. A observação dos estatutos legislativos revelou que não raro eram vagos, ambíguos e contraditórios. Năo havia objetivos claros a que os administradores pudessem subordinar-se. Por outro lado, a observação do comportamento administrativo mostrou que os conflitos em torno das diretrizes a serem adotadas continuava prevalecendo nos departamentos e ministérios. Os administradores tomavam decisões importantes, que afetavam profundamente a vida do povo. Tinham poder de escolha, e agarravam-se a ele. Na verdade eles próprios, muitas vezes, dividiam-se no tocante à maneira de interpretar as leis, de esquematizar suas diretrizes de acordo com elas. Grupos de interesses esforçavam-se vigorosamente para conseguir medidas administrativas que lhes fossem favoráveis. Além disso, não existia bastante conhecimento para determinar qual o melhor caminho a seguir para alcançar um objetivo geral em muitas áreas. Consideradas as

R. Serv. públ., Brasília, 109 (2) abr./jun. 1974 
grandes áreas de incerteza e ignorância, os valores e as alternativas dos administradores assumiam grande importância. Nesse nível não haveria muito a dizer para manter a distinção entre política e administração. Não obstante, perturbadoras dúvidas persistiam.

Política e administração se identificariam? Se assim fosse, como entender que pudéssemos falar delas separadamente? Ou política era simplesmente um termo que cobria tudo o que os diferentes órgãos do Governo faziam? Se política e administração podiam de alguma maneira, ser separadas, uma divisão de trabalho poderia basear-se nelas. Não há dúvida que a vontade legislativa, se afinal existia, poderia ser minada por uma série de determinações administrativas. Mas essas decisões não eram de menor porte e menos abrangentes que as do Congresso? Não haveria meios pelos quais as deliberações do Congresso se tornasse mais imperativas do que os atos dos administradores? O poder de discrição administrativa violentava a teoria democrática.

for Ao chegarmos à década de setenta, observaram-se, sem dúvida, esforços significativos para reabilitar a dicotomia política-administração. As insatisfações da moderna vida industrial estão sendo debitados à burocracia, que Parece ampliar-se diariamente enquanto a satisfação humana não aumenta proporcionalmente. Identificou-se a burocracia com o formalismo e a resistência às reformas. Contudo, ninguém imagina livrar-se dela em virtude da demanda sempre crescente de serviços. Assim, os políticos que acham que a burocracia tornou-se onerosa (3), a clientela que pensa que poderia ser melhor servida por outro sistema, os contribuintes que se ressentem dos custos exagerados, os analistas políticos que vêem as atuais organizações como obstáculos à aplicação da inteligência, aliar-se-ão na procura de meios destinados a fazer com que a burocracia se torne mais servivel. Seria melhor isto do que isolar suas funções supérfluas da massa do oficialismo? Em vez de evitar que a administração se contamine pela política, o propósito da nova dicotomia será defender as diretrizes da influência paralisante da burocracia.

\section{QUEM PAGARÁ O ONUS DA MUDANÇA ?}

Enquanto a maioria das organizações avalia periodicamente alguns de Seus planos, aquelas auto-avaliadoras devem fazê-lo continuamente. As atividades de avaliação seriam ineficazes, isto é, custariam mais do que valeriam Salvo se levassem a mudanças. Na verdade, tal organização é estabelecida Propositadamente com o objetivo de estimular mudanças.

A organização auto-avaliadora tem que convencer seus próprios integrantes a viverem sob constante mudança. Podem pensar que se aprecia ter constantes aborrecimentos quando ingressam na organização, mas a experiência thes ensinará que a coisa é diferente. O apetite do homem pela rápida mu- 
dança é estritamente limitado. As pessoas não podem suportar o desafio de suas crenças arraigadas, ou a alteração contínua de suas vidas. As rotinas de ontem são abandonadas e substituídas por outras novas. A ansiedade é induzida porque as pessoas não podem esgotar sua capacidade. Elas tem problemas por saber exatamente o que deveriam estar fazendo. A confusão que se segue pode levar a ineficiências sob a forma de hesitação ou comporta. mento dispersivo destinado a cobrir tantas áreas quanto possível. A descrença pode desenvolver-se na medida em que a sabedoria de anteontem cede lugar à nova verdade que, por sua vez, é substituída por uma outra ainda mais radiosa. Os líderes da organização que se avalia devem enfrentar esta crítica.

O estabelecimento de pontos de apoio para a política dentro de uma organização exige um sistema de vendagem interna de idéias. Os líderes devem convencer os membros da organização de que estão fazendo algo de meritório. Dentro da organização auto-avaliadora a tarefa pode ser, inicialmente, mais difícil do que nas burocracias tradicionais. Seu pessoal está acostumado a discutir proposições políticas e a exigir argumentos que as fundamentem. Uma vez a campanha inicial obtenha sucesso pode-se esperar que o entusiasmo. alcance um alto nivel depois que tenham sido avaliadas todas as diretrizes em vigor, analisadas novas alternativas e apresentadas provas em favor de uma determinada alternativa. O perigo, aqui, é supervalorizar. Convencidos de que a "ciência" está a seu favor, persuadidos de que seus cálculos estão afinados com o mundo, os avaliadores acreditam demais em suas próprias idéias. Eles estão preparados para maiores desapontamentos por parte daqueles que esperam menos. Quanto maior, então, a dificuldade, mais a avaliação contínua aponta a necessidade de nova mudança de diretrizes. Duas campanhas internas devem ser feitas : a primeira envolve a erradicação da antiga diretriz e a segunda a venda da idéia da nova. Todas as virtudes se tornam vícios insuspeitáveis e a boa mercadoria do ano que passou é agora vista como inapelavelmente ordinária. Reforma contínua tem seu preço.

A manutenção da alta taxa de modernização depende, criticamente, da competência dos respectivos autores para fazer com que outros paguem os custos acumulados. Se os reformadores são, eles próprios, obrigados a arcar com o ônus de suas providências, procurarão estabilizar a situação. Este é 0 refrão de toda a literatura de sociologia referente à organização, de Weber a Crozier. As necessidades dos indivíduos deslocam as metas da organizaçăo. Os propósitos oficiais a que supostamente os órgãos servem dão lugar a sels atos particulares. Suas agendas particulares dominam.

Em vez de sucumbir aos males da burocracia, a organização auto-ava liadora é tentada a transferi-los às outras. Ela pode dividir-se em partes avă liáveis e partes administráveis, fazendo assim com que os niveis inferiore $e^{\mathfrak{s}}$ paguem os custos da reforma, ou procurar impô-los a outros órgãos em sel meio. Devemos tratar primeiro da estabilização do escalão superior da orga nização enquanto os inferiores continuam fluindo. 
Vamos supor que uma organização separa sua equipe avaliadora de seu corpo administrativo. O pessoal de topo não exerce funções operacionais. Ele é no jargão administrativo, assessorial e não executivo. Sua tarefa é avaliar os resultados das diretrizes em vigor, planejar melhores alternativas e conseguir que as novas diretrizes sejam cumpridas pelas unidades operacionais.

Sobre quem recairia o ônus da mudança ? Pode-se imaginar avaliadores andando às voltas alegremente a sugerir mudanças para cá e para lá sem que sejam obrigados a implementá-las. A ansiedade seria absorvida pelos administradores. Eles seriam obrigados a fazer as mudanças e suplantar as dificuldades. Mas eles não estão dispostos a isso. Segundo sua convicção, o que é administrativamente factível e organizacionalmente praticável deve ser parte da política adotada. Assim, os administradores barganharão com os avaliadores.

Os administradores tem significativos recursos a lançar na luta. Eles lidam com o público. Eles coletam dados básicos que são enviados para cima de uma ou outra forma. Eles podem atrasar o serviço, mobilizar a clientela, reter informes ou, ainda, tornar difícil a cooperação. Os avaliadores tem suas próprias vantagens. Tem maior autoridade para expedir normas e instruções. São técnicos em manipulação de dados e modelos para justificar diretrizes ou para liquidá-las.

Responsáveis pelas direirizes mas impedidos de administrá-las diretamente, os avaliadores tem um incentivo para buscar sistemas antiburocráticos de prestação de serviços. Eles preferirão, por exemplo, um rendimento a uma estratégia de serviço (4). Os avaliadores estarão absolutamente certos de que os clientes receberão cheques pelo correio, remetidos pelo computador central, muito embora rão possam estar certos de que os serviços a que visam Serão prestados por contingentes burocráticos da maneira que desejariam. Dar ao povo renda para que possa adquirir casa própria tem a grande vantagein de não requerer um corpo de funcionários para supervisionar a construção. $\mathrm{O}_{S}$ avaliadores não dispõem de pessoal de campo para supervisionar inúmeros pequenos empreendimentos, por isso preferem investimentos em grandes proletos e não em pequenos. Eles podem, ainda, fazer melhor uso de seu pequeno número de funcionários em projetos custosos, que justifiquem a dedicação de muitas horas-análise. Contrariamente, os administradores realçarão operações de longo alcance que prestam serviços que requerem grande número de pessoas Q que só eles podem prestar. Numa casa de muitas moradas eles serão os senhores.

inverterá circunstâncias, naturalmente, em que administradores e avaliadores dores ana seus papéis. Se os avaliadores acham que não há bastante serviSo públicos, por exemplo, eles poderão adotar serviços extraordinários. os administradores acham que estão já carregados, aceitarão planos facilmente centralizáveis e dirigiveis por máquinas que executam operações de 
rotina. A tendência mais acentuada, entretanto, é para administradores e avaliadores invadirem os domínios um do outro. Cada um pode reduzir o poder de negociação do outro tomando-lhe as vantagens. Assim, os administradores podem recrutar seus próprios analistas para competir com os avaliadores, os quais, por sua vez, procurarão seus próprios contatos dentro da máquina administrativa a fim de assegurar um fluxo de informação constante e digno de confiança. Se esta luta vai longe o resultado serão duas organizações atuando mais ou menos da mesma maneira como o fazia a anterior, mas com problemas adicionais de coordenação.

\section{AVALIAC̣ÃO EMPRESADA}

Separar a avaliação de administração está apenas a um passo da idéia de equipes rivais de avaliadores. Um equivalente simples de mercado competitivo poderia ser introduzido, permitindo-se que equipes de avaliadores concorressem à formulação de diretrizes para uma determinada área. A competição se estabeleceria em termos de preço (podemos atingir determinado objetivo a baixo custo), qualidade (melhores diretrizes pelo mesmo custo), quantidade (podemos produzir mais pelo mesmo custo), manutenção (podemos controlar as coisas quando forem mal), experiência (temos comprovada idoneidade técnica), valores (nossa política incorpora suas preferências) e talento (ao final das contas você está pagando por nossa competência e nós somos superiores). A equipe que vencesse a competiçãu seria investida da responsabilidade até que desejasse afastar-se para trabalhar noutra parte ou até outra equipe a desafiasse. O governo poderia elevar o preço para manter uma equipe competente ou baixá-lo, para livrar-se de uma equipe incompetente. O estímulo à avaliação seria enorme, limitado, naturalmente, pela falibilidade de desempenho, a menos que os avaliadores viessem a falir, esgotados os seus recursos, oll perdessem clientela para seus competidores. A primeira tarefa da nova em. presa seria estabelecer sua própria forma de organização. Que disposições organizacionais seriam necessárias para tornar a competição factível entre avaliadores?

Os avaliadores devem ter emprego estável em alguma parte ou empenhar-se em outras ocupações eximíveis, das quais possam ser recrutaúos prontamente. Uma porção de avaliadores pode sempre ser recrutada por métodos "ad hoc" onde quer que sejam encontrados. Mas equipes de avaliadores suficientes para dirigir áreas importantes da política seriam difíceis de reunir a curto prazo. Eles estariam todos fazendo coisas diferentes, em vez de traba. Iharem juntos, o que é parte da experiência de que necessitam para obter sut cesso. Nem podem formar uma equipe, salvo se eles todos possam compro. meter-se a trabalhar um certo tempo, caso a retribuição interesse, embora ao mesmo tempo detenham outros empregos para os quais voltar se forein dispensados. 
No modelo anterior, onde os avaliadores criam novas políticas e os administradores as cumprem, esses burocratas arcam com a principal carga de incertezas. Sob o novo modelo, esse desequilíbrio é compensado porque os avaliadores tem que se preocupar com segurança de emprego. Poucas pessoas gostam de mudar de emprego a toda hora menos ainda da idéia de desemprego periódico, alternando com a ansiedade da concorrência a empregos e do bom desempenho para mantê-los. Serão encontrados mecanismos, podemos estar certos, para reduzir seu nível de incerteza a dimensões toleráveis.

Os avaliadores podem escolher trabalhar nas organizações administrativas existentes, aceitando uma posição mais baixa, aprendendo a conviver com desapontamentos em troca de estabilidade. Isto é um padrão que já existe. Eles podem ir para as empresas privadas e para a universidade sabendo que poderão fazer ocasionais incursões no governo como parte de um pequeno grupo de consultores das autoridades superiores. Isto é feito agora. Ambas as alternativas excluem a idéia de competição: apenas introduzem um pequeno elemento de avaliação em organizações existentes, na base do "vale-tudo".

A fim de proteger os avaliadores que estão em posição de competir pela direção da política, será necessário para eles formar suas próprias organizações estáveis.

Como as firmas de consultores em administração com que se assemelham, esses avaliadores concorreriam em numerosos projetos; a diferença seria que eles fariam o verdadeiro trabalho de política como parte da máquina oficial, em vez de fazer recomendações e desaparecer. A avaliação empresada, como a chamaremos, teria várias equipes, algumas trabalhando e outras aprestando-se para fazê-lo. A firma demandaria considerável volume de serviços Para dar trabalho a todos os avaliadores, elaborar propostas e compensar os membros que estivessem temporariamente sem trabalho. A meta organizacional da avaliação empresada será manter-se em estado de solvência, com um alto nivel de emprego. A empresa de avaliação é uma organização: possui dirigentes interessados em sobreviver, tem pessoal que deve ser convencido a permanecer a seu serviço, clientes que devem ser atendidos. Assim, constituir-se-á objeto de avaliação. Quando a procura de seus serviços é grande, poderá apurar sua ética de avaliação; prestará seus serviços àqueles preparados para apreciá-los (pagá-los bem). Mas quando a demanda é pouca, ela deve adaptar-se às circunstâncias, pois tem uma folha de pagamento a atender. Em vez de deixar um contrato quando prevalece um critério anti-avaliativo, pode ter que engolir seu orgulho e prosseguir. Seus diretores podem facilmente convencer-se de que a sobrevivência não é uma boa coisa apenas para eles, mas também para a sociedade, que se beneficiará do bem que poderão fazer em melhores oportunidades.

Se seus defeitos derivam de sua insegurança o remédio será claro: aumentar a estabilidade dos avaliadores garantindo-lhes o emprego. A identi-

R. Serv. públ., Brasilia, 109 (2) abr./jun. 1974 
ficação muito estreita com partido ou política, em qualquer caso, provar-se-á uma vantagem duvidosa, pois banqueteiam-se enquanto estão prestigiados e morrem de fome quando estão sem prestígio. Aparentemente exigem estatus de serviço público, uma empresa estatal, digamos, devotada à avaliação. Talvez o General Accounting Offices (GAO), que está começando a fazer estudos analíticos, forneça um modelo de organização governamental, autônoma de avaliação. Desde que tenha uma fonte segura de receita em seu trabalho de auditagem, por assim dizer, pode ter condições para formar, dissolver e recriar equipes de avaliadores. Sua autonomia no tocante ao Executivo (o ContadorGeral é subordinado ao Congresso e seu mandato é de quinze anos) poderia facilitar análises objetivas. Mas a autonomia do GAO tem sido mantida porque ele evita envolver-se em matéria controversa. Se o novo órgão central de avaliação - General Evaluation Office - GEO - emitisse relatórios que aumentassem o conflito haveria sem dúvida um forte empenho no sentido de submetê-lo a controle político regular. A velha funçáo de auditoria pode ser comprometida porque é difícil manter objetividade a respeito de um programa que se patrocina, ou porque discussões públicas afetam a confiança de que gozam. Os opositores da sua posição política podem começar a discutir sua imparcialidade em determinar a legalidade dos gastos do governo. Ademais, seria difícil conseguir apoio porque o novo órgão não tem clientes políticos.

Atentando para os problemas de uma organização que faż avaliaçăo para outras, esperamos lançar luz sobre os dilemas de qualquer organização que deseje seriamente empenhar-se na análise continua de suas próprias atividades.

A avaliação que critica certos programas e propõe substitui-los por outros é manifestamente uma atividade política. Se não é política no sentido partidário, ela o é no sentido de advocacia política. Sem uma firme base de apoio político, sem aquela essencial manifestação de estima por parte de alguém de fora na sociedade, sofrerá a sorte das crianças abandonadas: a organização que se avalia não prospera na orfandade.

\section{AJUSTAMENTO AO MEIO}

A organização auto-avaliadora é aquela que usa análises próprias de seus próprios programas para alterá-los ou aboli-los. Sua capacidade para realizar mudanças quando suas análises as indicam é parte essencial de sua capacidade para tornar a avaliação uma realidade. Entretanto, a capacidade de qualquer organização para auto-reformar-se é limitada pela necessidade de receber apoio de seu meio-ambiente.

Os líderes de uma organização auto-avaliadora não podem deixar os resultados de seu trabalho ao sabor dos fatos. Se não marcam boa média de pontos estarão em apuros. Os membros da organização perderão fé na avàR. Serv. públ., Brasília, 109 (2) abr./jun. 1974 
liação porque ela não leva à mudança da política. Os que são atraídos pela perspectiva de exercerem poder através da análise deixarão para aliar-se a coisa mais promissora e os clientes tradicionais ficarão mal satisfeitos sem que haja novos para ficar em seu lugar. A medida que os que crêem na avaliação vão-se afastando, o pessoal menos motivado por essa ética alcançará os altos postos e a revitalização da organização por via de promoção e recrutamento de avaliadores atuantes ficará impossivel.

A fim de evitar o ciclo mortal - fracasso, desespero, abandono os líderes da organização auto-avaliadora devem procurar assegurar algum sucesso, selecionando as atividades da organização não só por sua justificativa de análise, mas também com as vistas voltadas para a conquista de apoio básico de seu próprio meio. Daí eles passam a desenvolver avaliação seletiva. Eles devem proibir a aplicação maciça de recursos nas áreas em que vêm pouca possibilidade de sucesso. Devem escolher problemas fáceis de resolver Q reformas fáceis de executar porque não envolvem rompimentos radicais com 0 passado. Devem estar preparados para reter a divulgação dos resultados da avaliação quando a época não for oportuna. Devem estar prontos para aproveitar a ocasião para a reforma, quer as avaliações estejam formalmente concluidas ou não.

Pouco a pouco, parece, o comportamento dos líderes tornar-se-á semelhante ao dos demais funcionários da organização, autoridades que também procuram adaptar-se a seu meio:

O crescente conservadorismo das organizações que se avaliam está sujeito a causar tensões internas. Há certeza de haver desacordos no tocante ao comportamento cauteloso da organização. Ninguém, poderá dizer com certeza se os líderes aprcveitaram corretamente as oportunidades num meio que se modifica rapidamente. Se tentam fazer muito, arriscam-se a fracassos no mundo político. Se procuram fazer pouco, arriscam-se a abandonar suas próPrias crenças e perder o apoio de seus mais dedicados membros. Não é fácil manter o equilíbrio entre eficácia e iniciativa.

A organização auto-avaliadora não precisa ser, porém, espectadora passiva influenciada por seu meio ambiente. Pode procurar mobilizar interesses en favor dos programas que deseja adotar. Pode tentar neutralizar a oposição. Pode tentar persuadir sua atual clientela de que será melhor atendida, ou inocular desejo de ser servido por parte de novos beneficiários. Teme-se que sua reputação entre grupos de clientela não seja a melhor, entretanto, e isto Porque, como organização que se avalia, ela deve estar preparada para abandonar (ou modificar drasticamente) seus programas e com eles a clientela a que se destinam. Os clientes saberão que seu casamento com a organização é apenas de conveniência, que ela está interessada em relações mais vantajosas, ' que deverão estar sempre atentos para dosar sua afeição de acordo com o

R. Serv. públ., Brasília, 109 (2) abr./jun. 1974 
exato grau dos serviços recebidos. A organização que se avalia não pode esperar mais do que aquilo que dá. Na verdade, deve receber menos.

A avaliação jamais poderá ser plenamente recompensada. Na prática outras considerações prevalecem sobre a avaliação, mesmo onde os poderes constituidos gostariam de seguir seus ditames. As diretrizes preferidas pelas organizações auto-avaliadoras não são jamais as únicas aprovadas pelo governo, e há sempre inúmeras outras sendo criadas ou a criar. Algumas delas tornam-se inconsistentes em face dos ditames da avaliação. Consideremos o impacto da política fiscal sobre a análise. Suponhamos que é época de rigor financeiro: o governo decidiu reduzir as despesas e não permite propostas de novos gastos, não importa quão justificadas sejam. As reduções podem ser determinadas onde indicadas pela análise ou não. De outro lado, pode haver uma decisão política de aumento de despesas. O mérito substantivo de várias diretrizes tem sido subordinado às suas implicações financeiras imediatas.

A avaliação pode ser manejada como arma na guerra política por uma facção ou partido contra outra. É de particular interesse para a organização auto-avaliadora a abordagem unilateral da avaliação, que cria problemas internos. Não é raro, como foi recentemente o caso na Grã-Bretanhą, quando o Partido Conservador voltou ao poder para um governo, considerar a avaliação como um meio de diminuir a burocracia. Há uma regra de dois passos que pode ser adotada: as recomendaçōes da avaliação podem ser aceitas quando levam a uma redução e rejeitadas quando causam aumento de despesas. Em pouco tempo os integrantes da organização tornam-se relutantes em fornecer as informações porque serão usadas tendenciosamente. O êxito da avaliação repousa no reconhecimento comum de que a atividade está sendo desenvolvida para assegurar melhores procedimentos, quaisquer que sejam, e não em apoio de uma posição predeterminada. Se esse entendimento é violado, os escalóes inferiores se negarão a colaborar. Eles sonegarão informações ou simplesmente não procurarão apurá-las. O moral da organização auto-avaliadora estará ameaçado porque seus integrantes estão sendo levados a distorcer a essência de sua vocação.

É a mesma coisa em todo o mundo: os que analisam não são necessariamente recompensados nem os maus (os que não avaliam) punidos. Os lí. deres da organização auto-avaliadora, entretanto, devem redobrar seus esforços para obter ajuda política.

\section{CONJUGANDO CONHECIMENTO E PODER}

Tomar em consideração os requisitos necessários a uma organização auto-avaliadora é compreender por que elas são raras. Tais organizações, ao fim, são suscetíveis das mesmas tendências que as demais. Elas também devem promover a estabilização de seu ambiente, e assegurar a integração
R. Serv. públ., Brasília, 109
(2) abr./jun. 1974 
interna e o apoio externo. A avaliação deve ser, no máximo, um elemento dentro da organização administrativa. Entretanto não se pode dizer hoje em dia que ela vem sendo superenfatizada. Os vôos da imaginação não devem levar à crença de que há possibilidade iminente de atenção exagerada para a avaliação. Voltamos simplesmente a perguntar como um pouco mais e não um pouco menos pode ser introduzido nas organizações públicas. Como conciliar a integridade analítica e a eficácia política?

O avaliador procura conhecimento, mas também procura poder. Seu desejo de servir alia-se à sua vontade de exercer poder. Um não funciona sem o outro. Um estímulo principal para o exercício dessa atividade é que os resultados tornam-se política governamental. Não faz sentido elaborar prescrições para a administração pública por puro prazer pessoal. Sem conhecimento seria errado procurar o poder. Mas sem poder é mais difícil obter-se conhecimento. Por que fornecer informação valiosa a alguém que não nos pode ajudar nem prejudicar? O acesso à informação pode ser permitido apenas sob condição de alteração de metas. O avaliador está bem quando pode acumular recursos de modo que maior conhecimento leve a maior parcela de poder, o que, em contrapartida, aumenta seu acesso à informação. Ele está mal quando a busca ao poder leva ao sacrifício da avaliação. Seu problema político particular é como tirar o máximo de ambos (e não em demasia de qualquer dos dois), de modo que o conhecimento e o poder reforcem um ao outro, ao invés de enfraquecerem-se reciprocamente.

O processo político gera o conflito de interesses no trabalho de avaliação. O avaliador considera a análise como um meio de decidir sobre melhores diretrizes e vendê-las a outros. A clientela (funcionários, líderes de grupos, cúpula administrativa) a vê como meio de melhor compreender as chances possíveis, de modo que possam controlá-las. Falar de melhores diretrizes como se quem as determina não contasse só anuvia a questão.

O grupo avaliador dentro da organização espera poder mostrar aos dirigentes políticos o valor de suas atividades. Os políticos, em troca, esperam aprender sobre a conveniência dos programas que estão sendo avaliados. Mas sua idéia de conveniência inclui manifestamente o apoio que os programas geram para eles e as organizações de que participam. Assim, a avaliação deve ser manejada para produzir programas que juntem o interesse dos líderes politicos aos resultados da ação governamental, de outra forma eles rejeitarão a avaliação e os avaliadores.

Uma política bem definida é de certa forma determinante de seu próprio sucesso; o apoio que conquista ou perde na clientela informa os projetos futuros. Por seu impacto no ambiente futuro da organização, a política proposta afeta o tipo de trabalho que a organização está apta a executar. O avaliador ortodoxo, embora dedicado somente ao mérito intrínseco dos programas, deve considerar a interação de seus efeitos no seu desempenho profissional futuro.

R. Serv. públ., Brasília, 109 (2) abr./jun. 1974 
Assim como ele insistiria em estimar o impacto de dado elemento de um sistema sobre outro na sua análise, também deve considerar como suas recomendações presentes afetarão as futuras. Uma avaliação correta considera 0 impacto de uma política nas organizações responsáveis por ela.

Consideremos nesse contexto organizacional o tão discutido problema de diversos programas governamentais contribuindo para os mesmos fins sem que se possa controlá-los. Pode haver redundância onde alguns programas se sobrepõem, ao lado de áreas que não recebem atenção e para as quais não há programas. Há serviços demais numa área, e de menos em outra sem qualquer justificação. Sem avaliação ninguém pode realmente dizer se há programas demais ou de menos ou se seu conteúdo é apropriado. Mas uma avaliação que apurasse tudo isso levaria a nada, a menos que resultasse em processos institucionais diferentes para tratar o mesmo grupo de problemas.

Mesmo em seus próprios termos, então, a avaliação não deve estar ausente das organizaçōes em que ela é uma dependente para a implementação. A definição da organização e a análise dos métodos são partes do mesmo processo governamental. Se uma organização deseja reduzir sua identificação com programas (e respectiva clientela), por exemplo, de modo, que possa examinar diferentes linhas de ação, deve adotar uma estratégia para aquele fim.

A organização auto-avaliadora faria bem em não depender de um só tipo de clientela. Diversificação é sua estratégia. Quanto mais diversificados seus serviços, mais variada a sua clientela, menos dependerá de qualquer delas, mais facilmente mudará sua base de apoio. A diversificação gera a flexibilidade de ação.

Qualquer organização que produza um só produto, por assim dizer, que se dedica a uma área limitada de atividade não a abandonará espontaneamente. Sua sobrevivência, afinal, está ligada ao seu programa. Se esse programa falha a organização morre. Uma implicação destas considerações é que a sabedoria tradicional no que se refere às organizações governamentais necessita seriamente de uma revisão (5). Se o princípio básico da organização é que programas similares devem ser agrupados, como agora se crê, estas organizações se recusarão a mudar. Ao contrário, os órgãos devem ser estimulados a diversificar seus produtos e a aplicação de suas potencialidades. Se elas não se defrontam com declínio de demanda por todos os seus programas, estarão mais propensas a abandonar ou modificar alguns. Quanto mais variados os programas, menos ela dependerá de um deles e mais propensa estará à reforma.

Năo importa quão boa seja sua análise interna ou quão persuasiva seja a justificação que ela desenvolver perante si mesma quanto aos seus programas, é sempre desaconselhável que ela julgue a si mesma. A habilidade de agradar a si mesmo deve ceder lugar (ao menos numa sociedade demo. 
crática) ao julgamento por estranhos. Os que as criticam devem, portanto, reconhecer que têm papel essencial. A oposição é parte do processo de avaliação. A meta seria conseguir um nível mais inteligente e aprimoradamente analítico de defesa em ambos os lados. Análises diferentes podem, como salienta Harry Rowen, tornar-se parte do ajustamento mútuo decorrente do uso inteligente dos conflitos entre interesses organizados.

A competição, entretanto, por si só, não leva necessariamente a mudanças fundamentais. As organizações podem continuar na ofensiva crescendo sem melhorar, isto é, fazendo mais da mesma coisa. A mudança em que estão interessadas é uma mudança em quantidade. Todos conhecemos a arte de vender preocupada com novas técnicas e estruturas mais complexas, em que o dinamismo interno e os conceitos aparatosos são confundidos com novas idéias. A movimentação pode ser unıa proteção contra a mudança.

A competição, para levar a conseqüências desejáveis, deve verificar-se sob regras apropriadas, especificando quem pode fazer determinado tipo de operação. Ninguém advogaria a competição desenfreada entre unidades econômicas na ausência de um mercado que tornasse vantajoso socialmente para os participantes atingirem seus interesses pessoais, na expectativa de ganhos mútuos. Quando partes não diretamente representadas no mercado são afetadas, por exemplo, podem-se mudar as regras para atender a uma faixa mais larga de interesses.

A competição entre políticas contrárias e seus defensores dá-se numa arena que estabelece regras para o exercício de poder com respeito a decisões específicas. Os avaliadores devem, portanto, considerar como o seu critério preferencial para decisão será afetado pelas regras das áreas políticas em que devem operar.

Retornamos à política, parece. A menos que a obtenção de apoio para a política seja parte integrante de sua definição, seus proponentes estão-se expondo a decepções. Pensar numa grande idéia e depois preocupar-se com sua implementação é uma receita para o fracasso (6). Uma boa avaliação não só especifica os resultados desejados, mas indica os mecanismos institucionais para consegui-los.

Se você não sabe como avaliar é problema apenas seu, mas se você sabe, isto torna-se um problema para os outros. A avaliação é um problema da organização. Enquanto o cavaleiro solitário pode arriscar uma análise de vez em quando, deve ao longo do tempo institucionalizar seus esforços se deseja produzir. A importância preponderante da avaliação verifica-se dentro das organizações. É largamente rejeitada pelas organizações que carecem dela. Criar uma organização que avalie suas próprias atividades evidentemente requer comportamento correspondente. Se não há absolutamente avaliação, se há mas suas indicações, não são aplicadas ou se são aplicadas distorcidamente, o que

R. Serv. públ., Brasília, 109 (2) abr./jun. 1974 
se deve verificar em primeiro lugar não é o aparelhamento técnico, mas a organização.

Ela será a primeira mas não a única. Ela sempre é parte de uma sociedade maior que condiciona o que ela pode fazer. A avaliação é também um problema social. Enquanto a oposição da organização está em primeiro plano, não nos apercebemos do problema social subjacente. Se esta resistência inicial for vencida e organizações individuais se interessarem por avaliação, ainda assim ter-se-ia de enfrentar inúmeras resistências levantadas por forças sociais.

\section{AVALIAC̣ÃO E CONFIANC̣A}

Para a organização auto-avaliadora todo conhecimento é contingente. É sempre possível melhorar, mudar para melhor é objetivo permanente embora não necessariamente atingido. É a organização que busca o conhecimento por excelência. Os caminhos pelos quais o procura definem seu caráter.

Ela é mais descrente que confiante. Está sempre desafiando suas próprias convicções. A dúvida científica e não o dogma será sua característica marcante. Ela busca uma nova verdade, em vez de defender velhos erros. Seu principal trabalho é testar hipóteses.

Como a comunidade modelo dos estudiosos, a organização auto-avaliadora é aberta, verdadeira e manifesta. Declara de público suas conclusões, mostra como chegou a elas e dá às outras a oportunidade de refutá-las. Os custos e benefícios de programas alternativos para vários grupos na sociedade são indicados precisamente em razão do que o conhecimento disponível permita. Tudo estará na mesa, nada passará por baixo dela.

Há meios de assegurar a informação necessária? Pode-se criar o necessário conhecimento? A verdade libertará os homens? Tentar responder a estas perguntas profundas ultrapassaria os limites deste artigo. Mas gostaria de lembrar, como ilustração, que as respostas dependem seriamente da existência de confiança entre os grupos sociais e dentro das organizações. A aceitação da avaliação requer uma comunidade de invidíduos com os mesmos valores.

Uma vantagem da análise formal em que se especializam as organizações auto-avaliadoras é que ela não depende inteiramente do aprendizado empírico. Isto pode ser feito pelas organizações comuns. Criando modelos que abstraem do universo da avaliação os relacionamentos, os avaliadores buscam substituir a minipulação de seus modelos por acontecimentos do mundo real. Rejeitando alternativas que seus modelos indicam que funcionarão mal (ou não tão bem quanto outras) estes analistas economizam os parcos recursos e protegem o público contra atuações menos proveitosas. Basicamente entretanto, deve haver um apelo ao mundo empírico. Ninguém, nem os próprios

R. Serv. públ., Brasilia, 109 (2) abr./jun. 1974 
avaliadores, deseja testar suas teorias em grandes populações sem razões mais tangíveis para crer na sua eficácia (7).

Uma vez que o defeito das organizações comuns é que elas não aprendem bem pela experiência, aquela que se avalia procura ordenar essa experiência de forma a extrair conhecimento dela. A prova de que uma política é boa é que ela funciona quando testada. Mas nem tudo se pode testar onde quer que seja. Assim, os experimentos estão no cerne da avaliação. Eles são essenciais para relacionar as causas alegadas com os efeitos desejados no contexto da limitação de recursos.

A habilidade da organização auto-avaliadora para executar suas funções depende grandemente do clima de opinião favorável à experimentação. Se os recursos estão severamente restringidos, por exemplo, levando à relutância a novas tentativas, a organização não pode funcionar. Se prevalecesse a idéia de que as pessoas merecem sempre idêntico tratamento, para escolher outro exemplo, a experimentação estaria banida. Tomemos o exemplo do movimento por "escolas mais eficazes" em Nova lorque. A idéia era conduzir uma experiência para determinar se maiores recursos para as escolas melhoraria o aproveitamento de crianças pobres. Para assegurar o experimento os recursos teriam de ser fornecidos a alguns locais mas não em outros, de modo que houvesse grupos de controle. A demanda por igualdade de tratamento foi tão intensa, entretanto, que houve piquetes nas escolas, tomando o tratamento especial a algumas unidades como discriminação, evidenciando-se que a experiência deveria ser tentada em todas as escolas ou em nenhuma. É claro que os requisitos sociais de experimentação devem existir para que a organização exerça auto-avaliação eficaz. A menos que os grupos confiem uns nos outros, eles não permitirão experiências nem aceitarão seus resultados.

Apesar de se poder encontrar meios de obter conhecimento sem experimentação, a avaliação fica impossível sem informação adequada. Mas quanta informação bastará? As hierarquias existem para reduzir a informação. Se o homem de alto escalão tivesse de conhecer todos os detalhes dos dados disponíveis na área de alcance da organização, estaria liquidado.

A informação é depurada e resumida ao longo da linha hierárquica, mas detalhes importantes podem ser eliminados ou distorcidos. Uma das críticas mais freqüentes à organização é a de que os homens da cúpula não sabem o que está acontecendo. A informação é-lhes subtraída ou chega-lhes inexata, de modo que eles decidem com base em falsas impressões. O desejo de só dar boas notícias resulta na eliminação de informação que poderia colocar o seu portador em má situação. Os altos escalóes podem, contudo, recorrer a certos dispositivos como a sobreposição de fontes de informação ou a colocação de informantes nos níveis intermediários. Há limites a esses esforços, entretanto, porque os homens da cúpula só têm o tempo necessário para processar o que lhes foi comunicado, de modo que vacilam entre o medo de falta de informação e o de excesso dela. 
Como poderia a organização auto-avaliadora neutralizar a informação tendenciosa? Os seus integrantes deveriam ser recompensados pela revelação de dados desfavoráveis. Os responsáveis pelos dados devem ao menos, não ser punidos por dizer a verdade. Se eles são também os responsáveis pela aplicação da política não será possivel afastá-los por mau desempenho porque uma vez isto seja feito, seus sucessores estarão motivados para suprimir tal informação. Os homens da cúpula devem aceitar a culpa, ainda que não se sintam realmente responsáveis e mesmo que seu conceito fique comprometido. A simples idéia de hierarquia deve implicar aquela de mudança de papéis em que superior e subordinado trocam entre si, de modo que cada membro sabe que em breve estará no lugar do outro. A organização auto-avaliadora requer um extraordinário grau de confiança recíproca.

A proliferação delas pode ensejar a confiança social, alargando as áreas de acordo em relação às conseqüências da política vigente e os possíveis efeitos das reformas. Cálculos sobre quem e a que ponto se beneficiaria ajudariam na análise custo-benefício da política. A legitimidade de instituições públicas se estabeleceria porque elas resultariam de um processo analítico auto-consciente crescentemente reconhecido como tal. A avaliação propiciaria informação, melhoria e estabilização em meio à mudança. Parece idílico.

Mais informação, por si só, não leva a maior entendimento se a sociedade está naufragada em dissidências fundamentais. A medida que a tecnologia provê maior volume de informação, cresce a necessidade de interpretação. Submerso em excesso de informação, desconfiado dos outros, o cidadão pode alienar-se quando os líderes informam quão mal vão as coisas e quão bem poderiam ir. Quanto mais o cidadão confia nesses líderes e não nos funcionários do governo, maior é a possibilidade de suas diferenças se acirrarem em lugar de desaparecerem. A clarificação de objetivos pode facilitar a identificação dos conflitos sociais implícitos na distribuição da renda ou nas preferências culturais a respeito do ambiente ou dos diversos estilos de vida com relação a pontos de vista opostos de sociedade ideal.

\section{A avaliação não cria o acordo, ela o pressupõe.}

( ${ }^{*}$ Nota do Autor: Trabalho apresentado à Conferência Nacional da Sociedade Americana " de Administração Pública, em Nova lorque, a 24 de março de 1972, como parte do primeiro capítulo de um livro de Jeanne Nieanaber e Aaron Wildavsky "Buying Recreation: Budgeting and Evaluation in Federal Outdoor Recreation Policy". New York: Basic Books, a sair), este artigo é o resultado de reflexōes sobre o que, à primeira vista, pode parecer um problema completamente diferente. Comecei a estudar os orçamentos detalhados e os orçamentos-programa e sua difícil coexistência em diversos órgãos de recreação. $O$ orçamento tradicional era influenciado pela politica mas não fornecia fundamentos para o reexame das atividades; 0 orçamento programa não sofria influência e também não resultava em avaliação das atividades correntes. Em lugar de indagar que tipo de orçamento seria preferivel, entretanto, dirigi minha atenção para a questão mais fundamental de por que as organizaçōes comumente năo avaliam suas próprias atividades. 


\section{OBSERVAÇÕES}

(1) - Dan Horowitz, "Flexible Responsiveness and Militray Strategy: The Case of the Israeli Army", Policy Sciences. Vol. 1, n. 2 (1970) pp. 191-205.

(2) - Hans Thorelli, "Overall Planning and Management in Sweden", International Social Science Bulletin. Vol. VIII, n. 2 (1956).

(3) - A mudança mais dramática e patente foi na presidência americana. Os presidentes tem burocratizado demais seu desempenho. Dentro do Executivo existem agora grandes subunidades, caracterizadas pela especialização e divisão do trabalho, para tratar com os meios de informação e comunicação. Congresso, política interna e externa e outras mais. Ao mesmo tempo, os presidentes lutam pelo direito de intervir em qualquer nível do bloco executivo em bases esporádicas. Os administradores estão sendo pressionados a reformas, enquanto o presidente estabiliza seu ambiente. Assim, temos o Presidente Nixon dizendo que deseja que se faça algo a respeito do Bureau de Assuntos Indianos, como se não the competisse, ou conclamando os cidadãos a reelegê-lo para que ele os salve dos efeitos maléficos de sua própria burocracia. Ele deseja eximir-se de culpa pelos erros burocráticos e conservar o prestígio pelas reformas.

(4) - Ver Robert A. Levine, "Rethinking our Social Strategies", The Public Interest, $n .^{\circ} 10$ (1968).

(5) - William A. Niskanen, "Bureaucracy and Representative Government" (Chicago: Aldine Atherton, 1971).

(6) - Para maior debate sobre estas linhas veja Jeffrey L. Pressman e Aaron Wildavsky, "Implementation: The Economica Development Administration in Oakland (Berleley and Los Angeles: University of California Press, a sair).

(7) - Uma exceção se verifica na área de política de defesa onde o propósito da análise é evitar o teste de hipóteses que possam gerar crises. Uma vez testada a hipótese de guerra nuclear, os avaliadores não estão inclinados a rever sua análise. Ver Aaron Wildavsky, em "Pratical Consequences of The Theoretical Study of Defense Polick", Public Administration Review. Vol. XXV, n. 1 (março, 1965), pp. 90-103. 
